\title{
The Myth Of Lost Sales: Does Disk Copying Negatively Impact The Music Industry?
}

Stephen C. Betts, (E-mail: bettss@wpunj.edu), William Paterson University Zinaida Taran, (E-mail: ztaran@sjfc.edu), Saint John Fisher College

\begin{abstract}
The music industry contends that copied CDs represent lost sales. An exploration of the historical precedents, music industry assumptions and empirical evidence show a far more complex relationship. In this paper we look back at potential threats to the entertainment industry threats such as the advent of recording, radio and cassette recorders. We then examine the assumptions of the music industry's argument, supplemented by a survey of disk copying behavior. The results indicate that the underlying dynamics are more complex than the industry claims, including the possibility that disk copying can result in a net benefit to the CD industry.
\end{abstract}

\section{INTELLECTUAL PROPERTY RIGHTS AND THE MUSIC INDUSTRY}

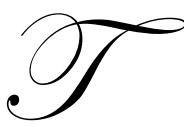

o provide a useful context for our consideration of disk copying, we will consider several episodes in the history of the copyright issues. Limiting our analysis to the music industry, the player piano was a threat to sheet music, recordings were a threat to live performers (Lessig, 2002) and radio was considered to be a threat to the recording industry when it was introduced in the 20s. Falling from $\$ 105.6$ million in 1921 to $\$ 5.5$ million in 1933, record sales indeed seemed to have been affected by this emerging threat, (Dowd, 2001). The recording industry still managed to survive and flourish, despite their claims that would destroy their market. Moreover, the promotional effects of playing songs on air on sales of records was so undeniable that, following extreme success of Capitol Records in the 40's record companies started to mail free records to radio DJs (Dowd, 2001).

Intellectual property rights follow the Constitutional Provision stating that "The Congress shall have Power... To promote the Progress of Science and useful Arts, by securing for limited Times to Authors and Inventors the exclusive Right to their respective Writings and Discoveries." (United States Constitution, article I, Section 8). However, although intuitively appealing, there is no evidence that the holders of copyrights need remuneration to continue to produce artistic works (Liebowitz, 2002). The long standing counter argument is that copyright is unnecessary because the market will provide returns without such protection (Hurt \& Schuchman, 1966; Plant, 1934). Taking into consideration the impact on "the potential market for or value of the copyrighted work" (Title 17, Copyright Law of the United States, § 107), the Fair Use Doctrine has been important in limiting the application of copyright laws when copyrighted work is used for non-commercial purposes. The Fair Use Doctrine was the basis of the Supreme Court's 1984 decision allowing consumers to use VCRs to tape television programs. Making tapes from purchased CDs for personal use has received the same protection (Wilson \& Healey, 2002) and many think that it should be extended to copying CDs. Despite the questionable claim of a loss in sales, a tax of $2 \%$ of manufacturers sales of CD recorders was to be collected for artist royalties since the Audio Home Recording Act of 1992 (AHRA) went into effect. $4 \%$ is to go to non-featured artists, $60 \%$ of the remainder is for record labels and $40 \%$ to featured artists (Boycott-RIAA, n.d.). As of 2003, according to Boycott-RIAA.com, no artist has received royalties.

More recently legal action taken by the RIAA (Recording Industry Association of America), the 'Napster' case, and generally the 'swapping' of digital music have made headlines, claiming a loss or potential lose of sales due to unauthorized copying of copyrighted material. However, there is no evidence of any loss of sales. In 1999 music 
sales were up 11\% (Boycott-RIAA, n.d.), first two quarters of 2000 up 9.9\% (Alexander, 2002). Although some styles of music may have dropped in recent years, these changes in sales are not consistent across styles of music. For example, alternative rock and soundtrack album sales increased, both in number of sales and percentage of sales from 2000 to 2001, whereas other styles fell slightly. This is notable because the buyers of alternative rock are also likely to have access to the technology used for copying.

The RIAA indicated at a Senate hearing in September of 2003, that they would refuse to negotiate licensing agreements with peer-to-peer services until a set of reforms that they dictate are adopted. Senator Norm Coleman (RMinn.), a member of the Investigations Subcommittee of the Senate Committee on Government Affairs, criticized the RIAA's use of lawsuits against consumers as "a strategy that uses the law to threaten people into submission" (Delaney, Goldstein, Gutterman \& Wagner, 2003). Although sales have not bee shown to decline due to the ability to copy digital material, the threat of prosecution by the RIAA resulted in a decrease in file swapping. Kazaa had 6.5 million users in the week before the RIAA warning, and 5.6 million afterward (Fetto, 2003).

\section{DISK COPYING}

In this paper we examine the impact of copying CDs on sales, as opposed to bootlegging and pirating. Bootlegging is the unauthorized recording, copying and selling of previously unreleased music. Recording of concerts is the primary form of bootlegging. Bootlegging is thought to increase product variety and has not been found to negatively affect legitimate sales (Naghavi \& Schulze, 2001). Pirating, the copying and selling of released music is clearly illegal and does crowd out legal sales because to the consumer they are equivalent. In this paper we consider disk copying the copying of a legally purchased $\mathrm{CD}$ for the owner's private use or to give to a friend at not cost to the friend. In this case, the copying replaces the owner transferring the CD from location to location or borrowing CDs among friends.

When a person receives a CD that they would have bought anyway, it is a loss in sales. However, when a person buys a CD after receiving a copy and liking it, it is an increase in sales. Buying another CD by the same artist also increases the sales. The simple model that we use for a preliminary indication of the effect on sales of disk copying is as follows:

- $\quad$ net effect on sales = gained sales - lost sales

- $\quad$ gained sales $=$ the percentage of time bought a $\mathrm{CD}$ because of receiving a copy plus the percentage of time bought another CD by the same artist because of the received CD.

- $\quad$ lost sales $=$ the percentage of time would have bought a CD if not received a copy

The contention that a copied CD results in a lost sale rests on the questionable assumption that an additional $\mathrm{CD}$ would have been bought if the copy was not made. In our model we acknowledge that this might be possible, but we also include the possibility that it would lead to additional sales. A more sophisticated model could include several other considerations. For example, regarding the buying behavior of the copier, there might be additional CD purchases based on the justification that the disk can be copied, or there might be a delay in purchasing in anticipation of receiving a copy.

\section{METHODS, ANALYSIS AND RESULTS}

In order to investigate the dynamics of CD copying behavior an anonymous survey was conducted during fall and winter of 2004. The survey contained questions about music CD purchasing and copying, music tastes and preferences and background information. The sample consisted of undergraduate and graduate students taking marketing and management classes in a mid-size public university and a small private college during 2004-2005 academic year.

The total sample size is 228 . The sample was $87.7 \%$ undergraduate students, $39.7 \%$ female vs. $60.3 \%$ male. $14.5 \%$ students report no employment, $56.1 \%$ are employed part-time, and $29.4 \%$ full time. $79 \%$ of the students identified themselves as Caucasian, $4.1 \%$ Asian, $6.8 \%$ Hispanic, $5.5 \%$ African-American and $4.5 \%$ other or a 
combination. Median age is 21 years, mean 22.5 years and the range is from 19 to 45 years. $90 \%$ of all students are not older than 27 . Overall, only $8.3 \%$ of the students indicated no ability to copy (however, out of those several indicated that they did make copies and provided all the related estimates).

Tables 1 and 2 summarize the survey questions dealing with CD related behavior. $87.6 \%$ of the respondents reported having made a copy of a music $\mathrm{CD}$, and $91.2 \%$ reported having received a copied music $\mathrm{CD}$. Therefore, this phenomenon is quite widely spread. The responses indicate that the ability to copy and receive copies causes individuals to hold off purchases in some situations and make purchases in others.

Table 1: Behaviors Related to Copying CDs

\begin{tabular}{|l|c|}
\hline \multicolumn{1}{|c|}{ Survey Item } & Yes \\
\hline Do you have the ability to copy CD & $91.6 \%$ \\
\hline Have you ever made a copy? & $87.6 \%$ \\
\hline Has your ability to copy ever prompted you to buy CD? & $32.0 \%$ \\
\hline Have you ever received a copied music CD? & $91.1 \%$ \\
\hline Have you ever not bought a music CD in anticipation of receiving copy? & $68.3 \%$ \\
\hline
\end{tabular}

Table 2: Frequencies of CD Purchases and Copying

\begin{tabular}{|l|c|c|}
\hline \multicolumn{1}{|c|}{ Survey Item } & Mean & S.D. \\
\hline Average number of CDs purchased a month & 0.97 & 1.50 \\
\hline Percentage of CD purchases copied & $47.7 \%$ & $37.8 \%$ \\
\hline Average number of copies made per CD & 0.98 & 0.76 \\
\hline Percentage of CD purchases prompted by the ability to copy CDs & $12.1 \%$ & $22.5 \%$ \\
\hline Percentage of CD collection that the respondent have received as copies & $35.2 \%$ & $31.7 \%$ \\
\hline Percentage of time would have bought a CD if not received a copy & $29.5 \%$ & $32.6 \%$ \\
\hline Percentage of time bought a CD because received a copy & $11.7 \%$ & $23.1 \%$ \\
\hline Percentage of time bought another CD by the same artist because received CD & $23.6 \%$ & $28.6 \%$ \\
\hline
\end{tabular}

Table 3 displays mean and standard deviations of the changes in sales under various assumptions regarding the number of CDs of the same artist that a person would buy per occurrence of buying a different CD from our survey. The minimum is, obviously, 1 , and a reasonable maximum is 2.1 .05 is when two different albums by the same artist are bought once out of twenty times.

Table 3: Change in Sales

\begin{tabular}{|c|c|c|}
\hline Mean Additional CDs Bought* & Mean Increase in Sales & S.D. Increase in Sales \\
\hline 1.00 & $6.5 \%$ & $43 \%$ \\
\hline 1.05 & $7.7 \%$ & $44 \%$ \\
\hline 1.10 & $8.9 \%$ & $45 \%$ \\
\hline 1.25 & $12.4 \%$ & $48 \%$ \\
\hline 1.50 & $18.3 \%$ & $53 \%$ \\
\hline 2.00 & $30.1 \%$ & $64 \%$ \\
\hline
\end{tabular}

*Various rates of purchasing by those who bought additional CD's by the same artist prompted by receiving a copy 


\section{DISCUSSION}

A strong fair use stance would allow for copying as long as no profit is being made by the copier. This research supports a strong fair use stance. The holder of the copyright is not being deprived of a share of the profits if there are no profits being made. The study showed an average increase in sales, therefore the music industry does not suffer. The distribution of the recording is not limited, therefore there is no violation of the waste prohibition and more potential consumers are exposed to the artists and genre. A strong fair use stance allowing for the copying of CDs by individuals for their private use and limited free distribution to friends would benefit both the recording industry and the consumer, creating a win-win situation.

"The issue at the heart of the copyright is the degree to which copyright owners can appropriate the value produced by the consumption, or appreciation, of their works by others" According to Liebowitz (2002 p.3). According to our study, on average the ability to copy disks positively affects sales. Congress and the courts are having problems coping with copyright law in the digital world. Although parties have been generally satisfied with specific recent decisions, it is unlikely that a case-by-case approach will suffice in the long run (Heidmiller, 2002). Our study supports the retrospective findings of the past that the threats to the music industry are not as severe as the industry would have us believe.

The discussion of copyrighting centers on the protection of the holder of the copyright, yet it might be the consumer who needs the protection. 85\% of all music is distributed by 5 major labels (BMG, EMI, Sony, Time Warner, UMG) (FTC, 2000), and they account for $95 \%$ of sales at the distributor level (Alexander, 2002). These five biggest music distributors were found to violate anti-trust laws. Their Minimum Advertised Price (MAP) policies, which restrict retailers from advertising below prices set by the distributors, were determined to be facilitating horizontal collusion and anticompetitive vertical restraints (FTC, 2000).

On average the ability to copy CDs increases sales, however the study is an aggregate of many possible situations. The dynamics of these situations differ greatly in how copying of CDs impacts sales. For example, the role of the promotional impact of receiving disks of little-known artists may be greater than that of popular titles which are constantly played on TV and radio allowing for familiarity prior to purchase. Rare disks would probably have an additional constraint on person's buying them by themselves in lieu of copying, as they might be willing but not able to purchase them.

Different dynamics depending on whether or not the particular artist and/or record is well-known, popular and available will have differential effect on sales according to our model. For unknown artists, especially those who have more than one $\mathrm{CD}$, the promotional effect of copied CDs will bring a bigger increase in sales. Hard to find rare records will not experience change in sales, as those who would get a copy would not have bought one by themselves. In the case where sales are lower, some promoters believe the wider exposure can stimulate concert sales (King, 2002).

"Nothing was made by God for Man to spoil or destroy" (Locke, 1690). A Lockean natural law argument can be made regarding intellectual property, and specifically applied to the major music labels. Damstedt (2003) advocates revisiting Locke because of the recent expansion of intellectual property protections and the academic emphasis on the importance of the public domain in limiting the expansion of private property rights. Locke's arguments often address the commons and some disregard Locke when considering intellectual property, reasoning that it is too extreme to consider the commons as equivalent to public domain. However, another notion that does have some merit is the waste prohibition. This can be interpreted as a prohibition against the waste of the product of labor, and specifically the intangible products because tangible goods can be bought and sold thus preventing their waste (Damstedt, 2003). At any given time, a great amount (some (Boycott-RIAA, n.d.) estimate as high as 80\%) of recorded music is not on the market with much of it being warehoused by the major record labels.

Warehousing is a waste of intellectual output and is facilitated by strong copyright laws and weak fair use interpretations. Society is deprived of the artists output and the artists whose work is not being distributed suffer. Although it may be an overstatement to say that society suffers when a CD is not available on store shelves, by 
extension there may be situations where suffer is an appropriate term. Consider legal rulings and arguments that facilitate the warehousing of recordings being used as precedents in support of warehousing drugs or inventions that could be of great help to many.

\section{LIMITATIONS AND FUTURE RESEARCH}

Our study used survey data which can be used to provide parameter estimates for Monte Carlo simulations. Monte-Carlo simulation involves multiple sampling of outcomes of a model whose independent variables are at least partially based on specified probability distributions (Bieker, 2002) and thus obtaining a distribution of the outcome variable. Because there might be underlying dependencies in the data, Bayesian techniques could be used. Bayesian analysis would used the relationships in the data to estimate the conditional probabilities under conditions of statistical dependence. Such a simulation could take into consideration the consumer heterogeneity with regards to their purchasing behavior, as well as categories of CDs therefore providing richer, more robust and more meaningful results. Complex relationships between different factors might be revealed, such as the relationship between types of music and changes in sales due to copying.

Another direction would be an extension of a one-period model to a dynamic multi-period model. Historical data on sales of CDs by categories will help simulate the actual distributions. A survey aimed at evaluating the empirical distributions and validating the model would need to include questions regarding past music purchasing behavior, behavioral intentions, familiarity with technologies and access to copying, as well as musical preferences. Elaboration of the model to include various antecedents of copying-related behavior will then be possible. Once relationships and distributions are established, the recording industry can examine use the dynamics and develop promotional and distribution strategies that maximize artist exposure, CD sales and concert attendance while still allowing consumers to copy CDs.

Explanations for various behaviors revealed in this survey and subsequent empirical investigations can prove valuable to practitioners. Various players in the CD industry could devise strategies that capitalize on the dynamics of disk copying behavior. The preliminary results found in this study indicate that it is quite possible to adopt a strong fair use stance and develop strategies for the CD industry to increase sales by allowing disk copying.

\section{REFERENCES}

1. Alexander, P.J. (2002). Peer-to-Peer File Sharing: The Case of the Music Recording Industry. Review Of Industrial Organization, 20 (2), 151-161.

2. Bieker, R. F. (2002). Using simulation as a tool in selecting a retirement age under defined benefit pension plans. Journal of Economics and Finance, 26(3), 334-343.

3. Boycott-RIAA. (n.d.) Retrieved March 08, 2004 from http://www.boycott-riaa.com.

4. Covel, S. (2003). For the bookmark: Web sites worth the click. American Demographics, 25 (4), 15.

5. Copyright Law of the United States of America (2003).

6. Damstedt, B.G. (2003). Limiting Locke: A natural law justification for the fair use doctrine. The Yale Law Journal, 112 (5), 1179-1221.

7. $\quad$ Decisioneering. (2004). Crystal Ball 2000.5. Denver, CO. Decisioneering

8. $\quad$ Dowd, T.J. (2001). The Napster episode. The Academic exchange, 2001, 6-7.

9. Delaney, E. M., C. E. Goldstein, J. Gutterman, S.N. Wagner (2003). Senate panel assesses standoff between file swappers and content owners. Intellectual Property \& Technology Law Journal, 15 (12), 16-17.

10. Delaney, E. M., C. E. Goldstein, J. Gutterman, S.N. Wagner (2003). Proposed copyright regulations set performance royalty rates for non-commercial Webcasters. Intellectual Property \& Technology Law Journal, $15(11), 15-16$.

11. Delaney, E. M., C. E. Goldstein, J. Gutterman, S.N. Wagner (2003). Recording industry responds to congressional inquiry regarding campaign to target individual copyrighted infringers. Intellectual Property \& Technology Law Journal, 15 (11), 15. 
12. Delaney, E. M., C. E. Goldstein, J. Gutterman, S.N. Wagner (2003). Copyright office issues final rules governing royalty payments for online music streaming. Intellectual Property \& Technology Law Journal, 15 (9), 16.

13. Fetto, J. (2003). Sharing is caring? American Demographics 25 (7), 15.

14. Heidmiller, S.M. (2002). Digital copying and file sharing on trial. Intellectual Property \& Technology Law Journal, 14 (4), 1-8.

15. Hurt, R.M. \& R.M. Schuchman (1966). The economic rationale of copyright. American Economic Review, 56, 421-432.

16. Katyal, N.K. (2003). Digital architecture as crime control. The Yale Law Journal, 112 (8), $2261-2289$.

17. King, T. (2002). Does CD copying and music on the internet really hurt the bands?, Retrieved March 08, 2004 from http://students.uwsp.edu/tking184/engwebsite.htm

18. Krishnan, R., M. D. Smith, R. Telang. (2003). The economics of peer-to-peer networks. Jitta: Journal of Information Technology Theory and Application, 5 (3), 31-44.

19. Liebowitz (2002) Re-thinking the Networked Economy: The Real Forces that Drive the Digital Marketplace, Amacom Press.

20. Naghavi, A.J., G. G. Schulze (2001). Bootlegging in the music industry: a note. European Journal of Law and Economics, 12 (1), p. 57.

21. Plant, A. (1934). The economic aspects of copyright in books. Economica, 1(2), 167-95.

22. Rogers, D. L. (2002). The DMCA and prohibitions of technology. Intellectual Property \& Technology Law Journal 14 (4), 9-18.

23. Sharp, J. (2002). Coming soon to pay-per-view: How the digital Millennium Copyright Act enables digital content owners to circumvent educational fair use. American Business Law Journal, 40 (1), 1-81.

24. Trudel, J.D. (2001). The Innovator's Dilemma: When New Technologies Cause Great Firms to Fail. Consulting To Management, 12 (1), 56-58.

25. Samuelson, P. (2002). Toward a "new deal" for copyright in the information age. Michigan Law Review, 100 (6), 1488-1505.

26. Williams, L. (1992). Software Management and Accountability. Industrial Management + Data Systems. 92 (4) $13-16$. 